due to the introduction of the Mental Health Act 1983, as the number and type of sections have altered little, but may be due to use of alternative managements on admission of formal patients. Mealtimes, however, remain a high risk period for seclusion.

Seclusion is being used less in Newcastle and will probably continue to decline as alternative management procedures are developed and used. While this is generally desirable it may be that not secluding certain patients leads to worse disturbance. The Mental Health Act 1983 does not seem to have had any direct effect upon the practice of seclusion but it is likely that it will indirectly modify attitudes and encourage further change. It seems likely that the decline is due mainly to a change in staff attitudes and thus response to disturbance, particularly non-violent acts, rather than any change in the patient population. However, it may be that the trends outlined are indications that disturbed patients are continuing to find their way into prisons rather than hospitals.

\section{REFERENCES}

'Royal College of Psychintrists (1980) Secure Facilities for Psychiatric Patients: A Comprehensive Policy. London: Royal College of Psychiatrists.

${ }^{2}$ ThOMpson, P. (1986) Seclusion: The use of seclusion in the Newcastle area. British Journal of Psychiatry, 149, 471-474.

${ }^{3}$ FotTRELL, E. (1980) A study of violent behaviour among patients in psychiatric hospitals. British Journal of Psychiatry, 136, 216-221.

\title{
Jobs and Computers
}

\section{Information technology training for long-term day hospital patients}

Maurice Lipsedge, Consultant Psychiatrist, Guy's Hospital, London; Angela B. Summerfield, Senior Lecturer in Psychology, Birkbeck College, University of London; G. LAZZARI, Undergraduate Student of Psychology, Birkbeck College and Honorary Student Psychologist, Guy's Hospital; and M. van BeEston, Undergraduate Student of Psychology, Birkbeck College and Honorary Student Psychologist, Guy’s Hospital

This is a report on a project which offers long-term day hospital patients a training which will lead to paid employment on the open market. Lack of work compounds the low self-esteem of chronic psychiatric patients. They experience multiple disadvantages, including loss of status, purpose, personal identity, social contacts outside the family, and a time structure to the day. Many of these disadvantages are known to be experienced by unemployed people in the general population. ${ }^{1}$ In most surveys, a fifth of the unemployed report a deterioration in their mental health since being unemployed, with an increased frequency of deterioration proportional to length of time without work. ${ }^{2}$ Work enhances self-esteem by decreasing the degree of dependency and by allowing identification with nonpatients and may influence perceived locus of control. Work provides social participation and is 'a visible measure of normality' for former patients. ${ }^{3}$

Long-term mental illness may itself involve loss of selfesteem and also deprive the patient of social roles in which he is valued by others. These disadvantages may be compounded by a socially-learned tendency to attribute control to external factors in the environment rather than the individual's own action. ${ }^{4}$ It has also been suggested that the reinforcing quality of an event is dependent on how responsible the individual feels for it, with externally attributed events being of lower value. Such an external locus of control would seem to be quite closely related to learned helplessness ${ }^{3}$ and it is possible that it can be modified by cognitive therapy, ${ }^{6}$ although little work has been done on this. Locus of control theory might then provide a useful framework for considering the extent to which psychi- atric patients perceive their circumstances as immutable, regardless of whether this is objectively the case.

The therapeutic value of work for chronic psychiatric patients was well recognised 30 years ago with, for example, the setting up of the first experimental workshop in Britain in Banstead. Simple repetitive work provides retraining and basic skills in 'work habituation', and in both health authority day hospitals and local authority social services department day centres, work has consisted of packing, sorting, labelling, or work with non-powered hand tools (such as staplers, hammers, needles) or domestic work, such as cleaning or sweeping. In occupational therapy, which involves craft work, a patient may be doing something purely for his own satisfaction, to meet his own expectations and to provide his own reward. ${ }^{7}$ This is an ability without a social role.

Since the 1960 s jobs have become progressively less available. Day hospitals seem to have become more involved in 'humanistic growth games' and craft work, and less concerned with preparation for productive activity. Traditionally, factory type work in an industrial workshop has provided the first stage of rehabilitation towards work on a production line, while some units have offered clerical work. With the decline in the availability of factory work, and with the spread of information technology, neither the traditional industrial nor the clerical approach seem adequate. Bennett ${ }^{8}$ has pointed out that the nature of the tasks often provided for schizophrenic patients underestimates their capacities. He refers to the difficulties in securing more complex work and adequately supervising it by nurses and occupational therapists: "It is quite possible, given 
skilled staff, to provide paid secretarial, clerical, research and data processing tasks, which are both acceptable and useful in the rehabilitation of university graduates".' With the development of the microcomputer, training in a marketable skill can now be made available, not only to the educational elite referred to by Bennett but also to those chronic psychiatric patients who might have left school without any formal qualifications whatever.

At present the computer and related industries are experiencing severe shortages of skilled staff. Personal Computer World, March 1986, reported over 12,000 unfilled jobs and the Department of Trade and Industry has expressed concern over failure to meet training targets. The reasons are complex and beyond the scope of this paper. They do, however, reflect both the rapid expansion of the industry and the lack of availability of qualified teaching staff. In addition some potential employees are deterred from training in information technology skills because of misconceptions about the nature of the work and doubts about the social consequences of the introduction of new technologies. In the former instance, potential trainees often assume that a much higher level of mathematical background is required than is in fact the case. This view is unfortunately compounded by the tendency of the engineers who write the instructional materials for computing to draw examples, quite unnecessarily, from mathematics and physics. In the second case, both Chapanis ${ }^{9}$ and Breakwell, Fife-Shaw, Lee \& Spencer ${ }^{10}$ have noted the complexity of attitudes to technological innovation. People favour the introduction of new technology while fearing possible increases in unemployment which it may bring about and the deskilling of jobs. In addition, many people are ill-informed about what precisely is involved in acquiring the new skills. Women are significantly less likely to have the opportunity of such training as noted by Breakwell $e t$ al, who cite data from the Central Statistical Office, 1985, and it is arguable that members of ethnic minorities are in a similar position.

It must be stressed that not all information technology training involves instruction in computer programming, a high-level skill. Many jobs in the industry involve the care of machines, the use of standard packages for such tasks as accountancy and record keeping and also data entry. Individuals with a relevant background are potentially employable by companies who use 'off-the-shelf' systems for routine tasks, as well as by high technology firms. In addition, such skills form a valuable adjunct to other skills which trainees may already have, such as typing or bookkeeping. Despite the attention supposedly paid to computer literacy in schools, there is evidence that school leavers competence is overestimated, with many only being motivated to play video games. Trainees with a more serious approach are therefore at an advantage. Six patients took part in our initial group at Speedwell Day Hospital, of whom five completed the course. The aim was to familiarise the patients with the use of a microcomputer, and to reduce their levels of anxiety with respect to modern technology as represented by the micro.

The following aspects were covered start and end of day routines: turning computer on and off, loading software, changing disks, using the printer; use of Apple introductory packages-'Introducing Apple', 'Inside Story' and 'Applesoft Tutorial'-to help patients to get to know the keyboard, reduce anxiety, and obtain some idea of the things they could do with the computer; use of the WordProcessing Package-'Format 80'; entering, running, saving, changing and printing BASIC programs; an introduction to spreadsheets, databases and graphics packages and the use of video equipment.

By the end of the training all five patients could manage to start up and turn off the Apple, load the word-processor, enter a document, format, change, save and print it. At varying levels, all the patients were familiar with the keyboard, slowness being caused by hesitancy as much as unfamiliarity. However, the two patients who had used a typewriter previously were at an advantage. We encouraged the others to use a typewriter if they had an opportunity. The patients were also introduced to an elementary graphics package. Most of the patients were able to type in (from a printed sheet) a BASIC program, alter mistakes, save, load, run, and print it. All the patients changed in their attitude towards the computer, and their approach changed dramatically.

They gained in confidence, and became less worried about 'breaking it' if they made mistakes. In fact most of them reached the stage of trying something out, without knowing what might happen-a change in cognitive style when interacting with a computer.

Some problems were encountered. For technical reasons, we were unable to use the Format $\mathbf{8 0}$ Word Processing package for some weeks and so had to cover more items on the programming side as we were a little short of alternative suitable material. Some more 'educational type' packages would have been helpful initially - the introductory packages were either very simplistic, and the patients soon tired of them, or were too complex. One micro amongst five patients was not sufficient. The four not using it at any one time often got very frustrated waiting their turn, especially when the user was particularly slow. One machine between two would have been ideal. One session a week, given that we had only the one computer, was not enough and we increased it to two sessions. However patients could get access at other times, but with the increasing knowledge and confidence of one member of the group, who took over and taught his fellows, the second session was probably not entirely necessary after a few weeks.

Differing levels of ability within the group were not as detrimental as they seemed initially. They enabled the patients to help one another, which they all did at some stage, and helped increase their confidence. The group got along very well with each other. When tension occurred, one member of the group was quick to dispel it with a joke. Their self-esteem improved, and interpersonal relations improved as well. In many respects they were just like a 'normal' group learning to use a computer, but were perhaps more hesitant. However, initially they seemed to be very insecure, and worried about making mistakes, but 
eventually learnt that 'trial and error' learning was the best approach. It would have been useful to have some practical task such as keeping accounts for the catering department for them to do that could be seen to be of use-sometimes the group activity seemed a little aimless. As this was the first group, we had teaching and organisational problems, from which we, the teachers, may well have learnt more than they, about running the next group.

The familiarisation courses held at Speedwell Day Hospital are designed to prepare patients for more extended training in the skills required by employers. Patients who have satisfactorily completed the Speedwell course are transfering to the nearby Outset Information Technology Centre for a one day a week nine month course. This centre is one of a chain funded by the Department of Trade and Industry. It specialises in the training of unemployed young people with few educational qualifications. In the country as a whole, approximately $\mathbf{8 0 \%}$ of trainees are placed in employment. Despite the very poor employment situation in Deptford, South East London (30\% of males are unemployed) $60 \%$ of trainees find jobs. In the longer term it is planned to extend the training to other psychiatric patients and possibly form links with other ITeCs.

To provide an objective measure of positive change in the way chronic day patients perceive themselves we are monitoring self-esteem using the scale devised by Rosenberg, as well as measuring prevailing $\operatorname{mood}^{11}$ and attitudes to technology. ${ }^{10}$ The project is already proving its viability and we anticipate that other day hospitals will be able to use this approach.

\section{REFERENCES}

1JAHODA, M. (1982) Employment and Unemployment, Cambridge: Cambridge University Press.

${ }^{2}$ JACKSON, P. R. \& WARR, P. B. (1984) Unemployment and psychological illhealth: the moderating role of duration and age. Psychological Medicine 14, 605-614.

3OLShANKSY, S. \& UNTERBERGER, H. (1963) The meaning of work and its implication for the ex-mental hospital patient. Journal of Mental Hygiene, 45, 139-149.

${ }^{4}$ Rotrer, J. (1966) Generalised expectancies for internal vs. external control of reinforcement. Psychological Monographs, 80, (1, whole, no. 609).

SSeligman, M. E. P. (1975) Helplessness: on Depression, Development \& Death. San Francisco: W. H. Freeman.

${ }^{6}$ Beck, A. T. (1976) Cognitive Therapy and the Emotional Disorders. New York: International Universities Press.

${ }^{7}$ BeNNETr, D. H. (1972) Day hospitals, day centres and workshops: general principles. In Non-residential services for the mentally ill: 1964-1971. In Evaluating a Community Psychiatric Service: The Camberwell Register 1964-71, (eds. J. K. Wing \& A. M. Hailey). London: Oxford University Press.

8 _ (1978) Social forms of psychiatric treatment. In Schizophrenia: Towards a New Synthesis. (ed. J. K. Wing). London: Academic Press.

${ }^{9}$ Chapanis, A. (1982) Computers and the common man. In Houston Symposium, 3, Information Technology and Psychology, Prospects for the Future. New York: Praeger.

${ }^{10}$ Breakwell, G. M., Fife-Shaw, G., LeE, T. \& Spence, J. (1986) Attitudes to new technology in relation to social beliefs and group memberships. Unpublished paper. University of Surrey.

${ }^{11}$ Beck, A. T., Ward, C. H., Mendelson, M., Mock, J. \& Erbaugh, J. (1961) An inventory for measuring depression. Archives of General Psychiatry 4, 561-571.

\section{New Addiction Unit in Surrey}

St Joseph's, a treatment centre for substance addiction and abuse, has recently opened in Haslemere, Surrey. The selfcontained centre provides accommodation and treatment facilities for up to 14 people and is also able to accommodate disabled people. Patients will be helped with detoxifcation and cared for during the initial phase of withdrawal. They will then follow a treatment programme, under the direction of a consultant psychiatrist, working with a team of counsellors headed by the Programme Director, John Wymark-Hoar. Special emphasis is placed upon the role and involvement of the family both in the treatment process and in after care support.

St Joseph's is part of Holy Cross, an independent nonprofit making hospital, owned by a charity, the Congregation of the Daughters of the Cross. Enquiries: Jennie Godden, Holy Cross Hospital, Haslemere, Surrey GU27 INQ (telephone (0428 3311).

\section{Community Mental Health Centres}

The National Unit for Psychiatric Research \& Development is planning a summer conference and exploring other avenues of collaborative work on Community Mental Health Centres. They are beginning with a small survey of all centres, planned or established, with the aim of identifying the range of different types of services in existence. They are therefore looking immediately for information on the whereabouts of centres and would also be interested in hearing from anyone in the field who might like to present a short paper on their centre at the conference.

Please contact: Liz Sayce at National Unit for Psychiatric Research and Development (NUPRD), Lewisham Hospital, London SE13 (telephone 01690 4311, extensions 6323 and 6335). 